\title{
Effects of maternal sleep deprivation on maternal sensitivity and contingent responsiveness
}

Cheryl Wiedman

West Virginia University

Follow this and additional works at: https://researchrepository.wvu.edu/etd

\section{Recommended Citation}

Wiedman, Cheryl, "Effects of maternal sleep deprivation on maternal sensitivity and contingent responsiveness" (2002). Graduate Theses, Dissertations, and Problem Reports. 811.

https://researchrepository.wvu.edu/etd/811

This Thesis is protected by copyright and/or related rights. It has been brought to you by the The Research Repository @ WVU with permission from the rights-holder(s). You are free to use this Thesis in any way that is permitted by the copyright and related rights legislation that applies to your use. For other uses you must obtain permission from the rights-holder(s) directly, unless additional rights are indicated by a Creative Commons license in the record and/ or on the work itself. This Thesis has been accepted for inclusion in WVU Graduate Theses, Dissertations, and Problem Reports collection by an authorized administrator of The Research Repository @ WVU. For more information, please contact researchrepository@mail.wvu.edu. 
Effects of Maternal Sleep Deprivation on Maternal Sensitivity and Contingent Responsiveness

\author{
Cheryl Wiedman
}

Thesis submitted to the Eberly College of Arts and Sciences at West Virginia University in partial fulfillment of the requirements for the degree of Masters of Arts in Life-Span Developmental Psychology

\author{
Katherine H. Karraker, Ph.D., Chair \\ JoNell Strough, Ph.D. \\ Lindsey Cohen, Ph.D. \\ Department of Psychology
}

Morgantown, West Virginia

2002

Keywords: Mother-infant interaction, Sleep deprivation, Maternal Sensitivity, Maternal Responsiveness Copyright 2002 Cheryl Wiedman 


\begin{abstract}
Effects of Maternal Sleep Deprivation on Maternal Sensitivity and Contingent Responsiveness

Cheryl Wiedman

Research has revealed that sleep deprivation deleteriously affects several aspects of adults' behavior, such as mood, cognition, and motor performance. One population that is subject to sleep deprivation and the accompanying consequences are parents of young infants. The present study explored how sleep deprivation, resulting from infant night awakening, affects the face-to-face interaction between mothers and their 3-to 4-month-old infants. Contrary to the proposed hypotheses the groups did not differ in sensitivity or contingent responsiveness. However, regression analyses revealed that depression and sleep deprivation together significantly predicted contingent responsiveness during the interaction. Mothers who were more depressed and sleep deprived were less likely than other mothers to smile or vocalize in response to an infant smile or vocalization. These findings suggest that maternal sleep deprivation, resulting from infant night awakening in combination with depression, suppresses their contingent responsiveness to their infants' social cues.
\end{abstract}




\section{Dedication}

This manuscript is dedicated in loving memory to my mother. Thank you mom for always believing in me and teaching me the true meaning of the word "courage." 


\section{Acknowledgements}

I would like to take this time to acknowledge all of the many individuals who helped complete this project over the year. First, I would like to thank my family and my fiancé for providing me with the loving support and encouragement I needed to overcome the challenges I faced during the duration of the project. I would also like to thank Dr. Katherine Karraker for her mentorship and her unending patience with my questions and concerns. I would like to thank the undergraduate students who made this project possible. I will always remember and appreciate Tina, Maanasi, Rachel, and Krista for their hard work and dedication. Finally, I would like to acknowledge the West Virginia University Department of Psychology's Alumni Fund for providing me with the funding necessary to complete the project. 
Table of Contents

Title Page

$\begin{array}{ll}\text { Abstract } & \text { ii }\end{array}$

$\begin{array}{ll}\text { Dedication } & \text { iii }\end{array}$

Acknowledgements $\quad$ iv

Table of Contents $\quad$ v-vii

List of Tables $\quad$ viii

Introduction $\quad 1-12$

Infant Sleep Patterns $\quad$ 2-3

Effects of Infant Sleep Patterns on Mothers 4

Maternal Interactional Style and Infant Development

Maternal Sensitivity $\quad 5-6$

Maternal Contingent Responsiveness $\quad$ 6-7

Difficulties in Mother-Infant Interaction $\quad 8-10$

Maternal Depression $\quad 8-9$

Sleep Deprivation and Maternal Depression $\quad 9-10$

Role of Infant Characteristics in Mother-Infant Interaction $\quad 10-11$

Statement of the Problem $11-12$

$\begin{array}{ll}\text { Hypotheses } & 12\end{array}$

$\begin{array}{lr}\text { Method } & 12-19\end{array}$

$\begin{array}{lr}\text { Participants } & 12-14\end{array}$

$\begin{array}{lr}\text { Procedures } & 14-15\end{array}$

Coding of Behavioral Data $\quad 15-17$ 
$\begin{array}{ll}\text { Coder Training } & 15\end{array}$

$\begin{array}{ll}\text { Maternal Sensitivity } & 16\end{array}$

$\begin{array}{ll}\text { Maternal Contingent Responsiveness } & 17\end{array}$

Measures $\quad 18-19$

$\begin{array}{lr}\text { Results } & 20-27\end{array}$

$\begin{array}{lr}\text { Descriptive Analyses } & 20-22\end{array}$

Tests of Hypotheses $\quad 22-24$

$\begin{array}{lr}\text { Exploratory Analyses } & \text { 25-27 }\end{array}$

$\begin{array}{lr}\text { Discussion } & \text { 27-34 }\end{array}$

$\begin{array}{lr}\text { References } & 35-39\end{array}$

$\begin{array}{ll}\text { Table } 1 & 40\end{array}$

$\begin{array}{ll}\text { Table } 2 & 41\end{array}$

$\begin{array}{ll}\text { Table } 3 & 42\end{array}$

$\begin{array}{ll}\text { Table } 4 & 43\end{array}$

$\begin{array}{ll}\text { Table } 5 & 44-45\end{array}$

$\begin{array}{lr}\text { Table } 6 & \text { 46-47 }\end{array}$

$\begin{array}{ll}\text { Table } 7 & 48\end{array}$

$\begin{array}{ll}\text { Table } 8 & 49\end{array}$

$\begin{array}{lr}\text { Table } 9 & 50\end{array}$

$\begin{array}{ll}\text { Table } 10 & 51\end{array}$

$\begin{array}{ll}\text { Table } 11 & 52\end{array}$

Appendix A: Screening Questionnaire $\quad$ 53-54

Appendix B: Background Questionnaire $\quad$ 55-59 
Appendix C: Rating of the Interaction (Mother) 60-62

Appendix D: Sensitivity Subscale from the Mother-Infant Rating Scale 


\section{List of Tables}

Table 1: Group Differences in Self-Report Ratings on the Demographic Questionnaire 40

Table 2: Group Differences in Self-Report Ratings on the Infant Care Diary 41

Table 3: Group Differences on the Verran/Snyder-Halpern Sleep Scale 42

Table 4: Group Differences on the Demographic Variables and Beck Depression Inventory 43

Table 5: The Distribution of Employment Status, Education Level, Spouse Education, Race, and Spouse Race in the Sample

Table 6: Mean Early Infancy Temperament Questionnaire Ratings

Table 7: Mean Group Differences on the Dependent Variables

Table 8: Descriptive Statistics on the Contingent Responsiveness Base Probabilities

Table 9: Summary of Regression Analyses for Sleep Deprivation and Maternal Depression Predicting Sensitivity and Contingent Responsiveness

Table 10: Coder 1 and Coder 2's Ratings of Sensitivity

Table 11: Intercorrelations between the Different Measures of Sleep 
Effects of Maternal Sleep Deprivation on Maternal Sensitivity and Contingent Responsiveness

Research in the general adult population has revealed that sleep deprivation affects several aspects of an individual's behavior. Pilcher and Huffcutt (1996) performed a metaanalysis to summarize data from 19 research studies that examined the effects of sleep deprivation on performance. Their analyses indicated that sleep deprivation could cause significant detriments in mood, cognition, and motor performance. Partial sleep deprivation (less than 5 hours of sleep in a 24-hour period) had stronger effects on cognitive performance and mood than did long-term (greater than 45 hours) or short-term (less than or equal to 45 hours) sleep deprivation. Bonnett (1989) also found that fragmented sleep resulted in significant deficits in performance and mood. The more the individual's sleep was fragmented, the more deficits in performance and mood were exhibited.

One population that is particularly subjected to partial sleep deprivation and fragmented sleep and the accompanying consequences are parents of young infants. Dement (1999) reported that parents of infants lose 2 hours of sleep per night over the first 5 months of infancy because the infant sleeps only about 8 fragmented hours per night. As a result these parents encounter many problems associated with sleep deprivation such as inability to focus, delayed and poor decision-making, indifference, and lack of motivation (Dement, 1999).

The present study sought to explore how sleep deprivation, resulting from infant night awakening, was affecting the interaction between mothers and their infants due to the mother's inability to focus on her infant and deficits in her mood. Research on postpartum depression has shown that mothers who are experiencing deficits in mood are less sensitive and respond to their infant in less immediate ways during interactions than do non-depressed mothers (Murray, FioriCowley, Hooper, \& Cooper, 1996; Nover, Shore, Timberlake \& Greenspan, 1984). This low 
sensitivity and lack of contingency shown by depressed mothers has been found to impair the infant's social and cognitive development (Murray et al., 1996). Postpartum depression research can be applied to the study of sleep deprivation effects on mother-infant interaction because the mother's mood and abilities to react sensitively and contingently toward her infant are most likely affected by her lack of sleep. Subsequently, the combination of low sensitivity and contingent responsiveness in the interaction could affect the infant who is dependent on the mother for cues about how to socially interact. In order to better understand the mechanisms underlying difficulties in mother-infant interaction as a function of maternal sleep deprivation, infant sleep patterns and their effects on the mother, characteristics of mother-infant interaction, and difficulties that can arise in the interaction will be discussed.

\section{Infant Sleep Patterns}

At birth, healthy full-term newborns sleep for 16-18 out of the 24 hours in a day and sleep-wake cycles tend to be between 3 and 4 hours. During the first month, sleep-wake cycles begin to adapt to light-dark cycles as well as other environmental cues. By the end of the first year, infants continue to sleep 14-15 out of the 24 hours in a day usually including 1-2 naps per day. By one year, most infants wake one or more times per night for 1-5 minutes at a time. However, $60-70 \%$ of those infants are able to self-soothe or comfort themselves back to sleep. Infants who are unable to fall back asleep without help are particularly problematic for parents (Anders \& Taylor, 1994).

Awakening during the night has been found to be highly individualized. A longitudinal study conducted by Bamford et al. (1990) reported that infants' total sleep and longest period of sleep were stable individual characteristics over time. They reported a high positive correlation between total sleep measured at 13,26, and 52 weeks. They also reported that infant sleep 
patterns tended to be set early in their life and that wakeful infants tend to continue to be wakeful throughout their first year. The number of sleep episodes at 6 weeks was positively correlated with the number of sleep episodes at 13,26, and 52 weeks. These results collectively indicate that once an infant's sleep patterns have been established they appear to remain relatively stable throughout their first year of life. Therefore, some infants who have difficulties in remaining asleep in the first weeks of their lives continue having difficulties in sleeping later in their lives, consequently adding to their parents' distress.

The pattern of remaining asleep through the night begins around 2 months of age. By this time infants' sleep patterns tend to be concentrated at night and waking normally occurs during the day. An infant is considered to be "sleeping through the night" if they sleep without removal from their crib between midnight and 5 AM for at least 4 weeks, whereas "night-waking" has been defined as arousal during that time with at least one weekly awakening for 4 weeks (Anders, 1979).

Problems arise when the process of nighttime consolidation fails to properly develop in some infants. These problems appear to be quite common given that by the time infants are 3 months of age approximately half of them are routinely awakening during the night (Karraker \& Cottrell, 2000). During this time, due to frequently interrupted sleep, the accumulation of sleep debt occurs in which parents of these awakening infants begin to experience the effects of partial sleep deprivation such as impairment of daytime functioning and mood (Dement, 1999). Researchers have found that mothers are more at risk for the deleterious effects of sleep deprivation than fathers because mothers awaken to care for their infants more than fathers. In particular, during the infant's first 3-4 months of life, many mothers are losing 2 hours of sleep per night (Ferber, 1985). 


\section{Effects of Infant Sleep Patterns on Mothers}

Researchers have found that maternal sleep deprivation and fatigue are directly related to postpartum depression and difficulties in mother-infant interaction (Goodlin-Jones, Eiben, \& Anders 1997; Karraker \& Cottrell, 2000; Nover, Shore, Timberlake \& Greenspan, 1984). The impact of maternal sleep deprivation on mother-infant interaction has particular significance in that not only might sleep deprivation be affecting the mother's interaction with her infant but it may also affect the infant as well. In order to better understand how maternal sleep deprivation may be affecting the dyadic interaction a discussion of the intricacies of mother-infant interaction is provided. The difficulties that arise within the interaction due to maternal sleep deprivation and subsequent mood disturbance and their relationship to infant outcomes will also be discussed.

\section{Maternal Interactional Style and Infant Development}

Research suggests that infant social development in the first year of life is affected by the quality of mother-infant interaction. During this time the infant observes the mother's affect and actively attempts to engage her in an interaction. Attempts to engage the mother in an interaction begin to take place around 3 months of age. At the same time, the quality and the amount of the infant's eye contact greatly increase, facilitating these interactional experiences (Volker, Keller, Lohaus, Cappenberg, \& Chasiotis, 1999). The interaction occurs in a sequence of behaviors. At 3 months, the infant initiates the sequence by looking at the mother. Once the infant is engaged with the mother she will respond in either a positive or negative way. If she responds with a positive expression, the infant will most likely respond with a positive expression as well. The dyad will remain in a state of positive expression until the infant terminates the behavior and the sequence begins again (Cohn \& Tronick, 1987). 
Three months is a significant time in infant development not only because infants are beginning to initiate social interactions with their mothers but also, as described above, their sleep cycles are also beginning to be regulated. Therefore, it is important during this time that the mother is able to appropriately respond to her infant's cues in order to facilitate the infant's social development. If the mother is sleep deprived, however, due to the frequent night awakenings of her infant, problems may arise in the mother's ability to respond to her infant's cues. Both the quality and the timing of the mother's affect influence the infant's responses during the interaction (Cohn, Cambell, Matias, \& Hopkins, 1990). In order to better understand the importance of these mechanisms underlying mother-infant interaction, a discussion of maternal sensitivity and contingency during dyadic interactions and their impact on the infant's social development is provided.

Maternal sensitivity. Maternal sensitivity has commonly been referred to in the literature as the mother's ability to swiftly and successfully respond to her infant's cues as well as to be affectionate and warm toward her infant (Atkinson et al., 2000). Murray (1998) has characterized sensitivity to be the mother's awareness of slight cues about the infant's readiness or disinclination to engage in an interaction. The mother is considered to be sensitive if she is able to interpret the needs of the infant and be appropriately responsive to those needs.

The mother's ability to successfully respond to her infant's cues has been associated with motivation, cognitive function, motor function, as well as social, emotional, and language development in the infant (Nover et al., 1984). One aspect of the infant's social development that has been extensively studied is the infant's level of attachment with the caregiver. Ainsworth was the first researcher to find evidence that mothers of securely attached 12-month-olds were more sensitive toward their infants during an interaction than mothers of insecurely attached 
infants (Ainsworth, 1974). In order to explore this relationship in greater detail, BraungartRieker, Garwood, Powers, and Wang (2001) conducted a longitudinal study of 94 families to examine how the degree of parental sensitivity, infant affect, and infant affect regulation at 4 months predicted attachment classification at one year. The results indicated that maternal sensitivity at 4 months significantly predicted security status at one year.

Maternal contingent responsiveness. The way in which a mother interacts with her infant influences the infant's capacity for learning as well. Research has shown that in order to understand cause and effect relationships infants must be exposed to events that occur regularly and closely in time (Hay, 1997). Infants' earliest experiences of perceiving these cause and effect relationships in their environment occur in social interactions with their parents. Infants gain an understanding of cause and effect relationships when their parents contingently respond to them. Contingent responsiveness has been defined as behaviors that are temporally and functionally related to the infant's signals (Dunham \& Dunham, 1990; Nover et al., 1984). In other words, contingent responsiveness is the parent's ability to identify their infant's cue or signal, interpret it correctly, and respond accordingly (Dunham \& Dunham, 1990). The way in which parents contingently respond to their infant's behavior tends to be stable within the dyad. The infant becomes familiar with contingent responses towards their behaviors and then generalizes those contingencies to new social and non-social stimuli (Bigelow, 1998). Bigelow has argued that from 3 months of age infants become sensitive to disruptions in the temporal order of behaviors in face-to-face interactions with their parents. Researchers have found that infants respond with distress and avoidance when this contingent aspect of the parent's interactive behavior is missing (Murray, Kempton, Woolgar, \& Hooper, 1993). Bigelow also contends that infants establish specific levels of awareness of contingencies based on their experiences with their parents. 
Infants therefore tend to be the most responsive to stimulation that has familiar levels of contingency. She tested this hypothesis by having 3-month-olds engage in face-to-face interactions with their mothers as well as strangers, looking at contingent smiling and vocalization behaviors exhibited during the interaction. She found that infants were more contingently responsive to strangers who exhibited similar contingent responsiveness as the mother. These results indicate that the infant is sensitive to specific levels of contingency. Bigelow further argued that infants who have parents who are highly contingent in their responding would show more interest in engaging in activities in their environments due to the fact that their actions produce obvious effects on their parents. In other words, Bigelow proposed that having parents who are highly contingent is beneficial to infants because it stimulates their curiosity and development. Dunham and Dunham (1990) similarly found that infants benefit from contingent responsiveness in face-to-face interactions with their mother. In a study involving vocal turn-taking the researchers found evidence to support the contention that social turn-taking is important to the infant's development because it affects the infant's understanding that their behavior has pronounced effects on the environment, as well as the likelihood that they will engage in other contingent interactions, and their ability to detect other contingencies in their environments.

Sensitivity and contingent responsiveness during mother-infant interaction appear to be directly related to mothers' abilities to identify, interpret, and respond to their infants' cues appropriately. However, there is a clear distinction between sensitivity and contingent responsiveness in that sensitivity is directed towards the affect of the infant and contingency involves the timing of the response towards the infant. Both are important during the interaction. For example, Murray (1993) contended that when a well-balanced interaction is present in the 
early months of an infant's life there is an increase in infant positive affect and attention towards the mother in comparison to dyads experiencing difficulties within the interaction. She also stated that when infants consistently experience contingencies between their behavior and environmental events it fosters their understanding of cause and effect relationships and facilitates cognitive functioning (Murray et al., 1993). Collectively, these findings emphasize the important influence of the mother-infant relationship in the early postpartum months on the infant's developing social interactions and understanding of cause and effect relationships in his or her environment.

\section{Difficulties in Mother-Infant Interaction}

It follows then, that mothers who are experiencing sleep deprivation may not be able to respond to their infants in sensitive and contingent ways given that both their mood and cognitive function may be impaired due to their lack of sleep. The symptoms that characterize depression such as sad mood, loss of interest, fatigue, low energy, poor concentration, and changes in motor or sleep patterns are likely to be related to less sensitive maternal care and negativity within the interaction (Appelbaum, Huston, Phillips, \& Vandell, 1999; Lovejoy, Graczyk, O’Hare, \& Neuman, 2000).

Maternal depression. Murray et al. (1993) reported that 10\% of mothers experience nonpsychotic depression in the 3-month period following delivery, which is the same time during which their infants' sleep patterns are becoming regulated. Murray found evidence to support the contention that non-clinically depressed mothers developed patterns of poor communication with their infants in the first few months following birth, which lead to impaired interactions that persisted and subsequently affected the infant's cognitive performance at 18 months (Murray, 1992). 
Further research on non-clinically depressed mothers has similarly discovered several difficulties in mother-infant interaction. A meta-analysis of 46 studies on maternal postpartum depression and parenting behavior revealed that depressed mothers of infants showed high levels of hostile and coercive behavior. Infants of non-clinically depressed mothers also experienced more disengagement from their mother, indicating that they were less likely to be involved in activity and play with their mothers (Lovejoy et al., 2000). Murray et al. (1996) found that mothers who were depressed expressed fewer affirmations and more negations towards their infant's behavior during an interaction. The mothers also tended to be either intrusive or remote during the interaction. They also found that the quality of the infant's communication was related to that of the mothers, indicating that the more sensitive the mother was the more actively engaged the infant was with her.

Sleep deprivation and maternal depression. The research presented above illustrates that the quality of the mother's communication toward her infant during the interaction appears to be directly related to her mood and ability to respond to her infant. One population that is affected by difficulties in mood and the ability to respond to their infants are sleep deprived mothers. In fact, researchers have found evidence to support the contention that sleep deprived mothers experience impairment of mood and respond to their infants in less immediate ways is related to their lack of sleep.

Similar to Murray's study of depressed mothers, Goodlin-Jones et al. (1997) examined maternal well-being and sleep-wake patterns in infants. They found that at 6 months maternal well-being was significantly related to how the mothers interacted with their infants at the start of the night, what occurred during the night, and whether the infant used a sleep aid. In particular, Goodlin-Jones et al. found that infants who were less likely to self-soothe during the 
night had mothers who reported higher levels of depressive feelings and stress. Another more recent study examining the impact of infant epilepsy on maternal functioning found that mothers' nighttime awakening was positively related to maternal depression and negatively related to mothers' perceptions of their sleep quality, marital satisfaction, and health (Cottrell, Atkins, \& Khan, 2002). Given these findings, sleep deprived mothers are evidently exhibiting depressive symptomology more than mothers who are not sleep deprived. Sleep deprived mothers also appear to be less able to focus their attention due to their lack of sleep, which appears to be associated with responding toward their infants in less immediate ways. For example, Nover et al. (1984) found that enduring sleep disturbances in 9-month-olds were significantly related to problems in the mother-infant interaction. In particular, they found that mothers of young infants with sleep disturbances tended to be less contingently responsive to their infants during exploratory play.

Given these findings, sleep deprivation is likely facilitating disturbances in mother-infant interaction. Some aspect of the infant's behavior (i.e., greater fussiness in infants who are unable to sleep through the night) could also be leading to difficulties in mother-infant interaction. To better understand the contributions of the infant to the difficulties exhibited during the interaction a discussion of infant characteristics follows.

\section{Role of Infant Characteristics in Mother-Infant Interaction}

The infant's inability to sleep through the night could be influencing the mother's behavior, independently of the sleep deprivation effects. It is possible that individual characteristics within the infant could be affecting the mother's mood and the way in which she is sensitive and contingently responsive toward her infant during an interaction, particularly if the infant is unresponsive or avoidant (Murray et al., 1993). The infant's level of irritability has 
also been found to significantly contribute to difficulties in the mother-infant relationship. A study of 180 non-clinically depressed mothers and their infants was conducted in order to assess the relationship between maternal depression and infant characteristics. The results revealed that infant irritability and poor motor performance were found to significantly predict maternal postpartum depression (Murray, Stanley, Hooper, King, \& Fiori-Cowley, 1996). These results indicate that infant temperament and poor motor skills can be upsetting to the mother, which may exacerbate maternal feelings of helplessness and distress.

More current research, however, provides evidence to the contrary. In particular, Murray (1998) revisited this bidirectionality issue in reporting results from a study examining depressed versus non-depressed mothers in interactions with their infants. She hypothesized that if the mother's behavior was motivated by infant characteristics then the quality of the mother's behavior during an interaction with her infant could be predicted by the nature of the infant's communication during an interaction with a stranger. The evidence indicated that the infant's communication with a stranger did not predict the quality of the mother's interaction, suggesting that infant characteristics did not significantly contribute to the quality of the mother's behavior. Given these conflicting findings, while examining mother-infant interactions researchers must take into consideration that both maternal characteristics and infant characteristics could be contributing to the success of the interaction. Therefore, the present study explored the effects of both infant and mother characteristics on the interaction.

\section{Statement of the Problem}

Research on postpartum depression has revealed that mothers who are depressed tend to be less sensitive and contingently responsive during face-to-face interactions with their infants than non-depressed mothers. Low sensitivity and lack of contingency during the interaction has 
been found to impair the infant's social and cognitive development (Murray et al., 1996). This research can be applied to sleep deprived mothers, as illustrated earlier, given that their social capabilities, mood, and attention are impaired due to their lack of sleep (Cottrell, Atkins, \& Khan, 2002; Goodlin-Jones et al. 1997). The combination of low sensitivity and lack of contingency could be affecting the infant's social development and learning.

There is an important need for research in this area in order to provide education and intervention about the effects of sleep deprivation to the public. The literature indicates that there are relationships between maternal sleep deprivation and maternal depression as well as maternal depression and poor mother-infant interaction. However, the possible relationship between maternal sleep deprivation and mother-infant interaction has gone unexplored thus far.

\section{Hypotheses}

The present study sought to explore how sleep deprivation, resulting from infant night awakening, might be affecting the level of sensitivity and contingency mothers exhibit during an interaction with their infants. It was predicted that 1) highly sleep deprived mothers would be less sensitive towards their infants than mothers who were not sleep deprived, 2) highly sleep deprived mothers would be less contingently responsive towards their infants than mothers who were not sleep deprived, and 3) highly sleep deprived mothers would report that they would have interacted better with their infant if they had received more sleep the night prior to the interaction.

\section{Method}

\section{Participants}

The sample consisted of 40 non-Hispanic white mothers (mean age $=30.58$ years, range 24 to 39 years) and their 3- to 4-month-old infants ( 25 girls and 15 boys) who lived in the 
Morgantown area. The mothers were employed fulltime (37.5\%), part-time (12.5\%) or were homemakers (50\%), with 4 years of college being the average education level. To control for problems associated with special cases such as prematurity (less than 37 gestational weeks) and other medical problems (i.e. any malady that required hospitalization for at least one week), only women who delivered healthy full term infants without complications were included in the study.

Participants were recruited via two means. During a routine visit with their infant to a local health establishment mothers were approached and asked to complete a brief questionnaire asking them to report demographic information as well as information about their infant's feeding/sleeping patterns, and a report of the amount of sleep they were getting. When the infant was 3 months old, mothers who met the criteria, described below, were telephoned and asked to participate in the study. County court records were also accessed to obtain the names of community members who had recently borne children. Addresses and phone numbers were obtained via the local telephone book and mothers were initially contacted using an introductory letter describing the study. The mother was telephoned when the infant was 3 months of age. The same screening questionnaire that was given to mothers at the doctor's office was verbally administered over the telephone (see Appendix A).

Regardless of the recruitment method, all mothers were categorized as highly or not sleep deprived based on their responses to the screening questionnaire. Mothers were categorized as highly sleep deprived if the difference between the average amount of nightly sleep they were receiving and the amount of sleep they reportedly needed to function well was 2 or more hours and their infant was awakening at least 2 times per night on average. Mothers were categorized as not sleep deprived when the difference between the average nightly sleep they were receiving and the amount of sleep they reportedly needed to function well was zero and their infant was 
awakening less than once per night (i.e. the infant was sleeping through the night at least once per week and didn't typically wake up multiple times during the night). After the screening questionnaire was completed, only mothers who fit the criteria for the highly or not sleep deprived groups were asked to participate in a study of maternal interaction with young infants. Mothers who did not fit either category were thanked for their time and were not invited to participate in the study. A total of 182 mothers were screened. One hundred of those mothers were not invited to participate because they did not meet the criteria or because their infant was born prematurely or had medical complications after birth. Of those mothers who did meet the criteria 28 declined to participate due to time constraints and 14 agreed to participate but later withdrew also due to time constraints. Of the 14 mothers who withdrew from the study, 6 were classified as highly sleep deprived and 8 were classified as not sleep deprived. Therefore, participant dropout did not appear to be systematic because a relatively equal number of women in each group declined participation.

\section{Procedures}

Mothers who agreed to participate were asked to attend a laboratory visit. One week prior to the visit, they received an information packet containing an introductory letter explaining the study, as well as several questionnaires that assessed their current sleep patterns and infant characteristics.

The laboratory visit consisted of a face-to face interaction in which the mother interacted with her infant. The scheduled visit occurred approximately two weeks after the mother initially agreed to participate with her infant. Visits were scheduled during the afternoon or early evening hours, given that it was the time when the effects of sleep deprivation were expected to be at their peak (Karraker \& Cottrell, 2000). During the interaction mothers were instructed to sit at a 
table with their infant situated in an infant seat directly in front of them. A mirror reflected the mother's facial expressions and vocalizations were heard with the aid of a baby monitor. The dyad was videotaped for 3 minutes through a one-way mirror during the face-to-face interaction. The mother was instructed to play with the infant and keep him or her entertained as they would at home without the use of toys. Following the interaction, mothers were then asked to complete several more questionnaires to obtain information pertaining to their demographic characteristics (see Appendix B), mood, previous night's sleep, and rating of the interaction with their infant (see Appendix C). Upon completion of the study mothers were reimbursed for their time commitment with $\$ 20$ as well as a booklet on infant development and the infants received a tshirt and certificate of participation.

\section{Coding of Behavioral Data}

Coder training. Videotapes were coded with the aid of two undergraduate laboratory assistants who were blind to the participants' group membership. The same two undergraduate students coded all of the videotapes using both the sensitivity and contingent responsiveness scales. The coders were instructed to code the tape using the sensitivity scale and then to rewind it to code for the contingent responsiveness behaviors. The primary investigator trained each student for approximately 1 month using videotaped recordings of mothers who agreed to engage in interactions with their infants for pilot testing of the study. These mothers were not included in the final sample. A total of four pilot interactions were used for training. First, each coder reviewed the tapes independently. Reliabilities for each scale were then assessed. The coders then assessed each of the pilot tapes jointly so that they could arrive at a mutual agreement for the sensitivity scale and the contingent responsiveness behaviors for each of the pilot participants. The coders then independently reassessed each pilot tape and when they reached 
reliability (i.e. Kappa coefficient's were greater than .60) they were allowed to code the participant tapes from the actual sample. Throughout the remainder of the study $20 \%$ of the tapes (4 highly sleep deprived and 4 not sleep deprived) were randomly selected to assess coder reliability using the methods described below.

Maternal sensitivity. Maternal sensitivity was coded using the Mother-Infant Rating Scale designed by Pianta and Egeland (1990) for use in the Mother-Child Project and was used in the current project. The Mother-Infant Rating Scale contains 12 scales. Only the general sensitivity scale was used to ascertain the mother's quality of responsiveness toward her infant's state and cues (see Appendix D). This scale is designed to rate the mother's sensitivity on a 1-to 9-point scale. A mother is rated as a 1 when she is "completely inattentive and insensitive to the baby's state and play." She is rated as a 9 when she is "sensitive to the baby's states and needs at all times." The authors reported interrater reliability to be defined as less than a 2-point discrepancy for the above scale and was calculated, using the Tinsley-Weiss index of agreement, to be .66. However, in the present study sensitivity was coded in three 1-minute intervals in order to increase the variability in ratings. Therefore, an overall mean score was computed. To calculate the mean score for each participant coder 1's rating was added to coder 2's rating and the product was then divided by 2 . High scores on the scale indicated high levels of sensitivity. Given that a mean was computed to assess the mother's overall sensitivity for the 3-minute interval a Pearson product moment correlation had to be calculated to assess agreement between coders because the use of a kappa coefficient was not feasible given the nature of the derived variable. Therefore the results of the Pearson Product Moment Correlation revealed that the relationship between the raters was $r=.39, p<.05$. 
Maternal contingent responsiveness. Contingent responsiveness was coded using an event sequential design where the presence or absence of maternal and infant smiles and vocalizations was recorded. Each 3-minute interaction was coded in 3-second intervals, yielding a total of 60 intervals. Three seconds was chosen because it has been shown to be the best time period to capture contingencies (Van Egeren, Barrat, \& Roach, 2001). The primary investigator trained laboratory assistants to record the presence of maternal and infant vocalizations and smiles using the following criteria. A smile was defined as an upturn of the lips with the mouth open and cheeks pushed up. A vocalization was defined as being any noise delivered by the mouth that did not include bodily functions or crying. Vocalizations and smiles were coded as present only when the coder physically saw them or when they were verbally made reference to by the mother (i.e. "Thank you for that smile" or "Are you smiling at me?"). Due to the lack of precision in timing the video recording only the first 56 intervals were coded in order to insure consistency in coding between participants. Also, due to one infant becoming upset during the later part of the interaction one participant's data could only be coded for 1 minute and 30 seconds. Therefore, in order to include her in the sequential analyses her contingency data was duplicated for the remaining intervals. Disagreements between raters were resolved by having a third coder recode intervals with disagreements. The primary investigator watched the videotaped intervals where the coders had a disagreement and made the final judgment about whether the smile or vocalization was present or absent. Interrater reliability for infant smiles, infant vocalizations, maternal smiles, and maternal vocalizations prior to resolution of disagreements was $.78, .65, .60$, and .39 respectively. Kappa coefficients of .6 were considered to be adequate (Cohen, 1960). The kappa for mother vocalizations was low because mothers tended to vocalize during the entire interaction, given the nature of the task. Therefore, during 
the few intervals when that behavior was absent the coders were unable to code the lack of vocalization at a rate better than chance.

\section{Measures}

The Infant Care Diary (Karraker \& Cottrell, 2000) was used to assess the maternal and infant sleep patterns one week prior to the laboratory visit. From this measure the mother's total sleep time per night, total wake time per night, total wake frequency per night, and total nap time per day were calculated. Measures of the infant's total sleep and wake times as well as total wake frequencies per night were also calculated.

The Verran/ Snyder-Halpern Sleep Scale (Snyder-Halpern \& Verran, 1987) is a 15 -item self-report measure, which obtained information about the mother's previous night's sleep and was completed at the laboratory visit. The items were combined into three scales assessing disturbance, effectiveness, and supplementation. The disturbance scale provides information about the participant's perception of the degree of disturbed sleep she experienced due to fragmentation and difficulty falling asleep. It is measured using seven items: mid-sleep awakening, wake after sleep onset, movement during sleep, soundness of sleep, quality of disturbance, sleep latency, and quality of latency. The effectiveness scale assesses the participant's perception of how effective she considered her sleep to be given the quality and length of the sleep. It is measured by five characteristics: rest upon awakening, subjective quality of sleep, sleep sufficiency evaluation, total sleep time, and total sleep period. Finally, the supplementation scale assesses the participant's perception of how her sleep was improved with additional sleep times, which is measured by four characteristics: daytime sleep, morning sleep, afternoon sleep and wake after final arousal. Snyder-Halpern \& Verran (1987) reported theta 
coefficients illustrating consistency for each scale to be .86 for disturbance, .75 for effectiveness, and .45 for supplementation.

To ascertain the extent to which sleep deprived mothers were experiencing depression, the Beck Depression Inventory-II (BDI-II) was administered following the face-to-face interaction. This measure is a frequently used depression assessment that requires the participants to rate their feelings on a 4-point Likert scale ranging from 0 to 3. Individuals with scores of 20 or above are considered to be suffering from moderate levels of depression. Individuals with scores of 9 or lower are considered to be nondepressed. Beck, Steer, and Garbin (1988) reported internal consistency for the BDI-II to be .92 for outpatient populations and .93 for college students.

To assess individual differences in infant characteristics that could have contributed to difficulties within the interaction, mothers were asked to rate their infant's characteristics using the Early Infancy Temperament Questionnaire (Medoff-Cooper, Carey, \& McDevitt, 1993). This questionnaire is used to assess the infant's temperament between 1 and 4 months of age. The mother was asked to complete the 86-item questionnaire by rating her infant on a 6-point Likert scale yielding ratings for activity, rhythmicity, approach, adaptability, intensity, mood, distractibility, and threshold. The authors report the internal consistency of these scales to be .48 , $.76, .44, .65, .43, .70, .46$, and .47 respectively. At the end of the questionnaire the mothers are also asked to rate several general impressions of their infant's temperament. The general impression scales include items pertaining to the infant's activity, rhythmicity, approach, adaptability, intensity, mood, distractibility, and threshold as well as how manageable they think their infant is in comparison with other infants known to the mother who are the same age. 
Results

\section{Descriptive Analyses}

To confirm the classification of participants as highly sleep deprived or not sleep deprived descriptive analyses were conducted in which participants' responses on the demographic questionnaire, Infant Care Diary, and Verran/Snyder-Halpern Sleep Scale were subjected to t-tests. Based on their responses to the demographic questionnaire this sample of mothers was receiving on average 6.38 hours of sleep per night. There were significant differences between the groups in the average amount of sleep per night they reported receiving on the demographic questionnaire. These and other group differences are reported in Table 1. The highly sleep deprived mothers were receiving less sleep than the not deprived mothers. The groups also significantly differed in their self-reported ratings of sleep deprivation, the number of times they were being awakened per week, the number of hours they needed to function well, how sleep deprivation was negatively affecting their function, and the number of naps they received per week. Highly sleep deprived mothers rated themselves on a 5-point scale with 5 being "very sleep deprived" to be more sleep deprived than the not deprived mothers. In addition, the highly sleep deprived mothers reported on a 5-point scale with 5 being " a great deal" that their everyday functioning was being negatively affected by sleep deprivation more than the not deprived mothers.

A review of the Infant Care Diary results confirmed the findings from the demographic questionnaire. In the week prior to the laboratory visit there were significant differences between the groups in mothers' total amount of sleep and infant awakenings per night. The highly sleep deprived mothers were receiving less sleep and were being awakened more by their infants per night than the not deprived mothers (see Table 2). In addition, the groups significantly differed 
in their scores on the disturbance, effectiveness, and supplementation subscales of the Verran/Snyder-Halpern Sleep Scale. The subscale scores on the disturbance and effectiveness scales revealed that the sleep of the highly sleep deprived mothers was more disturbed and less effective than that of the not deprived mothers. The subscale scores on the supplementation scale also revealed that the highly sleep deprived mothers augmented their total sleep time with additional sleep times (i.e. daytime, morning, and afternoon sleep) more than the not deprived mothers (see Table 3 ).

In addition, to provide an integrity check on each of the sleep measures, Pearson Product Moment Correlations were calculated. The results revealed that there were significant relationships between each of the measures of sleep indicating that they were indeed adequately measuring the amount of sleep the mothers were receiving (see Table 11).

Despite the significant group differences in the total amount of sleep and the number of night awakenings the groups did not differ on any other demographic variables. They did not significantly differ in employment status $t(38)=1.23, p>.05$, education level $t(38)=.92, p>.05$, race/ethnicity $t(38)=1.00, p>.05$ spouse education $t(38)=1.81, p>.05$, or spouse race/ethnicity $t$ $(38)=.99, p>.05$ (see Table 5 for the frequency of responses). In addition, there were no group differences between age and income (see Table 4). Also, in congruence with Beck et al.'s (1988) criteria for the Beck Depression Inventory individuals who scored 20 were considered to be suffering from moderate depressive symptoms and individuals with scores of 9 or lower were considered to have no depressive symptoms. However, there were no significant differences between the groups on mean scores of the Beck Depression Inventory (see Table 4)

There also were no differences between the groups in terms of infant gender or temperament. Infant gender was not related to group membership, $x^{2}(1, \mathrm{~N}=40)=.11, p>.05$, or 
infant manageability $t(37)=-1.01, p>.05$. There also were no group differences in infant temperament except for manageability. Highly sleep deprived mothers rated their infants on a 1to 6-point scale with 6 being "very difficult" as more difficult than did the not deprived mothers (see Table 6).

Tests of hypotheses

To determine if sleep deprivation was affecting mother-infant interaction the present study sought to examine how highly sleep deprived versus not sleep deprived mothers differed in sensitivity and contingent responsiveness while interacting with their infants.

Maternal sensitivity. It was hypothesized that highly sleep deprived mothers would be less sensitive towards their infants than mothers who were not sleep deprived. The coders' ratings were averaged and subjected to a t-test, which indicated that there were no significant differences between the groups in ratings of sensitivity (see Table 7). There were no significant group differences in sensitivity displayed by the mothers towards their infants during the interaction. Each coder's rating of sensitivity was then subjected to a t-test to examine whether there were significant group differences depending on which coder rated the data. The results revealed that there were no significant group differences in sensitivity as rated by coder 1 and there were no significant group differences in sensitivity as rated by coder 2 (see Table 10).

Contingent responsiveness. It was also hypothesized that highly sleep deprived mothers would be less contingently responsive towards their infants than mothers who are not sleep deprived. Base probabilities were computed first, in which the total number of intervals in which each behavior occurred was calculated and divided by the total number of intervals. There were no significant differences between the groups for the base probabilities of infant smile, infant vocalization, infant smile or vocalization, mother smile, mother vocalization, or mother smile or 
vocalization (see Table 8). Contingent responsiveness was then examined by using transitional probabilities, in which the probability that an infant behavior was followed by a mother behavior was calculated and adjusted for the base probability of both behaviors by computing $z \operatorname{scores}$ (Bakeman \& Gottman, 1987). The $z$ scores were subjected to t-tests and the results revealed that none of the transitional probabilities differed across groups (see Table 7).

Mothers' ratings of the interaction. The final hypothesis proposed that highly sleep deprived mothers would report that they would have interacted better with their infant if they had received more sleep prior to the interaction. A t-test was conducted that assessed group differences in the mothers' ratings in response to the following statement: "I would have had a higher quality interaction with my infant if I had gotten more sleep last night.” Ratings ranged from 1 "strongly disagree" to 5 "strongly agree." The results revealed that there were no significant differences between the groups' ratings (see Table 7). Overall, mothers did not agree that their previous night's sleep was influencing the interaction they had with their infants on the day of the laboratory visit.

In addition to the above statement, mothers were also asked to rate their agreement with statements on the demographic questionnaire that provided information about the amount of sleep they were receiving and how it was affecting their functioning. One question asked them to rate their response to the following question, "If you think you are sleep deprived to what extent do you think your everyday functioning is being negatively affected?" Ratings ranged from 1 "not at all" to 5 "a great deal." Mothers were also asked to rate their response to this question, "If you think you are sleep deprived to what extent do you feel it is interfering with your ability to interact with your baby?" Ratings again ranged from 1 "not at all” to 5 "a great deal." 
Correlational analyses were conducted to determine whether there were any relationships between the mothers' responses to the above items on the demographic questionnaire and the mothers' responses to the question that asked whether their interaction was influenced by the amount of sleep they were receiving. The results revealed that maternal ratings of sleep deprivation negatively affecting their everyday functioning was positively correlated with maternal ratings of sleep deprivation interfering with their ability to interact with their infant, $r=$ $.69, p<.001$. As the mothers' ratings of sleep negatively affecting their everyday functioning increased so did their ratings of sleep deprivation interfering with their ability to interact with their infant. There was also a positive correlation between maternal ratings of sleep deprivation negatively affecting their functioning and the agreement with the sleep statement stated above, $r$ $=.43, p<.05$. As the mothers' ratings of sleep deprivation negatively affecting their functioning increased so did their ratings of agreement to the statement that they would have had a higher quality interaction with their infant if they had gotten more sleep. Finally, there was a significant positive correlation between maternal agreement with the sleep statement and the extent to which sleep deprivation was interfering with their ability to interact with their baby, $r=.63, p<.001$. As the mothers' ratings of the extent to which sleep deprivation was interfering with their ability to interact with their infant increased so did their agreement to the statement that they would have had a higher quality interaction with their infant if they had gotten more sleep. Although there were no group differences in mother's ratings of sleep deprivation affecting the interaction there did appear to be relationships between mothers' reports of sleep deprivation and ratings of the interaction they had with their infants. 


\section{Exploratory Analyses}

Further analyses were conducted to examine whether there were any other factors contributing to how sleep deprivation may be affecting mother-infant interaction. Given that there were significant differences between the groups with infant temperament, with the highly sleep deprived mothers rating their infants as more difficult than the not deprived mothers, follow-up analyses using the General Linear Model were conducted. Temperament was entered as a continuous predictor, to determine whether it was interacting with the mother's sleep status and was influencing the mother's level of sensitivity during the interaction. An alpha level of .05 was used for all analyses. The results indicated that there were no main effects for sleep status, $F$ $(1,35)=.03, p=.85$ or temperament $F(1,35)=2.28, p=.14$. An examination of the interaction effects revealed that there were no differences related to the infant's temperament and mother's sleep status, $F(1,35)=.08, p=.78$.

The same analysis was conducted to examine whether the infant's temperament was interacting with the mother's sleep status and was influencing her level of contingent responsiveness during the interaction. There were no main effects for sleep status on the z-scores for the transitional probabilities for infant smile followed by a mother smile, $F(1,35)=1.40, p=$. 26 , infant smile followed by a mother vocalization $F(1,35)=.00, p=.99$, infant vocalization followed by a mother smile $F(1,35)=2.41, p=.15$, or infant smile or vocalization followed by a mother smile or vocalization $F(1,35)=1.57, p=.23$. However, there was a main effect for infant vocalization followed by a mother vocalization $F(1,35)=6.77, p=.02$. The mother's sleep status did appear to be influencing her vocalizations in response to her infant's vocalizations. There were no main effects for temperament on the z-scores for the transitional probabilities for infant smile followed by a mother smile $F(1,35)=.63, p=.44$, infant vocalization followed by a mother 
smile $F(1,35)=.02, p=.88$, infant vocalization followed by a mother vocalization $F(1,35)=1.33$, $p=.27$, or infant smile or vocalization followed by a mother smile or vocalization $F(1,35)=2.78$, $p=.12$. However, there was a main effect for infant smile followed by a mother vocalization $F$ $(1,35)=11.15, p=.01$. The mother's ratings of her infant's manageability did appear to be influencing her vocalizations in response to her infant's smiles.

Although there were main effects for sleep status and temperament, an analysis of the interaction effects revealed that there were no differences in the z-scores for the transitional probabilities for infant smile followed by a mother smile, $F(1,13)=1.24, p=.29$, infant smile followed by a mother vocalization, $F(1,13)=.21, p=.65$, infant vocalization followed by a mother smile, $F(1,13)=1.86, p=.20$, infant vocalization followed by a mother vocalization, $F$ $(1,13)=3.21, p=.10$, and infant smile or vocalization followed by a mother smile or vocalization, $F(1,13)=.08, p=.79$. Despite the apparent main effects for sleep status and infant temperament they did not appear to be interacting with one another. Ratings of infant manageability did not appear impact how highly sleep deprived or not sleep deprived mothers responded toward their infants during the interaction.

Regression analyses were also conducted to determine whether maternal depression and sleep deprivation predicted levels of sensitivity and contingent responsiveness during the interaction. An alpha level of .05 was used for all of the regression analyses. In addition, the analyses were conducted using all of the participants' combined data and were not conducted for each group separately. In the first analysis, depression and sleep deprivation were entered as predictors of sensitivity. The results revealed that depression, $t(38)=-1.20 p=.24$, and sleep deprivation, $t(38)=-.63, p=.54$, did not significantly predict sensitivity during the interaction either alone or in combination, $R^{2}=.04$ (see Table 9). Maternal depression and sleep deprivation 
did not contribute to the mother's sensitivity during the interaction. Subsequent analyses entered depression and sleep deprivation as predictors of the $z$-scores of infant smile followed by mother smile, infant smile followed by mother vocalization, infant vocalization followed by mother smile, infant vocalization followed by mother vocalization, and infant smile or vocalization followed by mother smile or vocalization. The results revealed that depression and sleep deprivation did not significantly predict infant smile followed by mother smile, infant smile followed by mother vocalization, infant vocalization followed by mother smile, or infant vocalization followed by mother vocalization. However, both maternal depression, $t(20)=-2.15$, $p<.05$, and sleep deprivation, $t(20)=-2.27, p<.05$, significantly contributed to the equation for infant smile or vocalization followed by mother smile or vocalization, $R^{2}=.28$ (see Table 9). Mothers who were more depressed and sleep deprived were less likely than other mothers to smile or vocalize in response to an infant smile or vocalization.

\section{Discussion}

Past research has shown that the quality of the mother's communication with her infant during an interaction is directly related to her mood and ability to respond to her infant. In particular, research focusing on one aspect of the mother's mood, depression, has found that it influences the quality (i.e. sensitivity) and timeliness (i.e. contingent responsiveness) of the mother's response toward her infant during an interaction (Lovejoy et al, 2000; Murray, 1996). One group of individuals that is affected by difficulties in mood and the ability to respond to their infants is sleep deprived mothers. The research has shown that there are relationships between maternal sleep deprivation and maternal depression. In particular, mothers who are awakening frequently during the night report having more depressive symptoms (Cottrell, Atkins, \& Khan, 2002; Goodlin-Jones et al., 1997; Nover et al., 1984). It follows then that if 
mothers who are depressed have poor interactions with their infants then mothers who are sleep deprived and are likely to be exhibiting depressive symptoms might also be having poor interactions with their infants. However, this possible relationship between maternal sleep deprivation and mother-infant interaction has gone unexplored thus far. The present study however did seek to investigate how sleep deprivation, resulting from infant night awakening, was affecting the interaction between mothers and their infants.

The data did not support the hypotheses that highly sleep deprived mothers would be less sensitive and contingently responsive toward their infants than not sleep deprived mothers. It also did not support the hypothesis that highly sleep deprived mothers would rate the interaction with their infants as less positive than the not sleep deprived mothers due to their lack of sleep. Despite the lack of significant results for this hypothesized group difference, follow- up correlational analyses did indicate that there were relationships between maternal ratings of how sleep deprivation was negatively affecting their everyday functioning and ratings of their interaction with their infants. Specifically, as maternal ratings of sleep deprivation negatively affecting their functioning increased so did their agreement that it was interfering with their ability to interact with their infant. In addition, mothers who indicated that sleep deprivation was affecting their ability to interact with their infant also indicated that they would have had a higher quality interaction with their infant during the laboratory visit if they had gotten more sleep. Although there was no evidence to support the predicted group differences in the mother's ratings of the interaction with her infant, there was evidence to support the contention that there is a relationship between mothers' perceptions of sleep deprivation affecting their everyday functioning and interactions they have with their infants. 
Despite the lack of support for the hypothesized group differences in sensitivity, contingent responsiveness, and ratings of the interaction, several factors did influence the level of contingent responsiveness mothers showed toward their infants during the interaction. The main effect for infant temperament revealed that mothers' ratings of their infant's manageability influenced the level of contingent responsiveness during the interaction, specifically when the infant smiled. This finding provides support for the argument that infant characteristics also contribute to the quality of mother-infant interaction. For example, Belsky (1984) reported that mothers who rated their infants as more difficult had more negative interactions with them. In particular, mothers of "difficult" infants were less responsive to their infant's cues and interacted less with them than mothers of "easy" infants. It is possible that certain mothers in the present study were less responsive toward their infant's smiles because they perceived their infant as being more difficult in comparison to mothers of infants who perceived their infant as being easy.

Another factor that appeared to influence the mother's level of contingent responsiveness during the interaction was her group membership. The main effect for sleep status suggested that the mother's sleep status did appear to influence her vocalizations in response to her infant's vocalizations. Finally, the results of the regression analyses indicated that both sleep deprivation and maternal depression predicted contingent responsiveness during the interaction, specifically when the infant smile or vocalized. Mothers who had more depressive symptoms and were more sleep deprived were less likely than other mothers to smile or vocalize in response to an infant smile or vocalization. Both of these findings confirm the contention that maternal sleep disturbances appear to be related to problems in mother-infant interaction, which is congruent 
with Nover et al.'s (1984) finding that mothers of young infants with sleep disturbances were less contingently responsive toward their infants during a play session.

There are several limitations to the present study. First, the reliability of the measure used to screen the mothers was questionable. There were differences between the mothers' responses on the screening questionnaire that was given two weeks prior to the laboratory visit and the other measures of sleep they were asked to complete the week prior to and the day of the laboratory visit. The mothers' responses on the screening questionnaire were used to assign their group membership. However, the variability in responses on the sleep measures became problematic when some mothers who were categorized as highly sleep deprived on the screening questionnaire actually would have fallen into a moderately sleep deprived group (i.e. less than 1 hour difference between the amount of sleep they were receiving and the amount of sleep they reportedly needed to function well as well as their infant waking at least once per night) based on their responses on the demographic questionnaire they completed on the day of the laboratory visit. Therefore, the measure used to assess sleep deprivation (i.e. screening questionnaire) was not reliable, which contributed to the groups not being as extreme as desired. Second, the sensitivity measure was unreliable. Despite extensive training in which the coders rated several tapes together the coders tended to rate all the mothers at the higher end of the scale with scores ranging between 6 and 9. Given this difficulty it appears that there could have been homogeneity in the sample. In particular, it is possible that this sample of mothers were so sensitive to their infant's cues that there was no way to distinguish sensitivity ratings between participants. Therefore, the coders were unable to reliably distinguish between ratings at the higher end of the scale. Multiple measures of sensitivity would have been more beneficial because each could have provided a check on the other (Judd, Smith, \& Kidder, 1991). Third, 
another possible explanation for the lack of group differences in sensitivity could be contributed to sample characteristics. All of the participants were of higher socio-economic status as well as education level, and therefore it is possible that they were more educated about attending to their infants' cues. Also, all of the participants volunteered for the study and knew that they would be videotaped interacting with their infants. Therefore, it is possible that this sample of mothers was more sensitive than mothers who did not volunteer for the study or were being more sensitive towards their infant's cues given that they were being videotaped. Fourth, the directions given to the mothers prior to the interaction could have also contributed to the lack of group differences. All of the mothers were instructed to "Keep your infant entertained as you would at home without the use of toys." Perhaps the mothers were more sensitive toward their infants because there were no distractions such as toys, older children, or other household interruptions. Fifth, one limitation that could have affected the contingent responsiveness results was that only two behaviors were coded. Smiling and vocalization occurred at a low frequency for the majority of the infants and at a high frequency for the majority of the mothers, again probably due to the instructions given prior to the interaction. This is consistent with Van Egeren, Barratt, and Roach's (2001) work that found during face-to-face interactions smiling was the least contingent behavior for both infants and mothers. Therefore, if the infant did not smile or vocalize during the interaction or if the mother smiled or vocalized the whole time their data could not be used in some of the analyses using the transitional probabilities. Finally, it is also possible that the mothers or infants were responding to each other in ways that were not coded (i.e. eye contact or touching).

One alternative explanation for why there were no significant differences between the groups in sensitivity and contingent responsiveness could be that sleep deprivation is not 
affecting the sensitivity and timeliness of the mother's response toward her infant. Despite apparent deficits in reports of everyday functioning and mood mothers were still able to respond to their infant's cues and perhaps only in cases of clinical depression or severe sleep deprivation are their responses delayed. Another explanation for the lack of significant findings in sensitivity and contingent responsiveness could be that the task was not lengthy enough for the mothers to be affected by their sleep deprivation. Pilcher and Huffcutt (1996) found in their meta-analysis of sleep deprivation studies that the effects of sleep deprivation were influenced by the type and length of the task. Therefore, it is possible that if the interaction task had been longer and less stimulating the effects of the mothers' sleep deprivation might have influenced her sensitivity and contingent responsiveness toward her infant's cues.

A final alternative explanation for the lack of significant findings could be related to the criteria for group membership. It is possible that the groups were not extreme enough in their differences between the average amount of sleep they were receiving and the amount of sleep they needed to function well as well as the number of times their infants were awakening at night. Perhaps if members of the highly sleep deprived group were being awakened 3 or more times per night and the difference between the amount of sleep they needed to function well and the amount of sleep they were getting was 3 or more hours there would have been apparent differences in their sensitivity and contingent responsiveness during the interaction with their infants in comparison to the not deprived mothers. The same applies to the not sleep deprived group. If the criteria were changed so that the not sleep deprived mothers were not being awakened at all by their infants and were receiving the same amount of sleep as they reported that they needed to function well there would have been apparent differences in their sensitivity and contingent responsiveness during the interaction in comparison to the highly sleep deprived 
mothers. In addition to the stricter sleep criteria, criteria for nap taking should have also been included. A review of the number of naps reported by the mothers in each group revealed that the highly sleep deprived mothers were taking more naps than the mothers who were not sleep deprived. Given this, it is possible that the naps could have negated or reduced the sleep deprivation that was being experienced by the mothers. Perhaps, if the mothers in the highly sleep deprived group were unable to take naps during the week then there would have been more apparent differences in their sensitivity and contingent responsiveness toward their infants during the interaction in comparison to the not sleep deprived mothers.

The findings that sleep status influenced the mothers' responses to their infants' smiles and that both sleep deprivation and depression contributed to the mother's timeliness in responding towards infant smiling and vocalization is important because past research has shown that contingent responsiveness impacts infant's social learning. For example, Dunham and Dunham (1990) found evidence to support the contention that social turn-taking is important to the infant's development because it affects the infant's understanding that their behavior has pronounced effects on the environment, as well as the likelihood that they will engage in other contingent interactions, and their ability to detect other contingencies in their environments. Future research should continue to examine the intricacies of mother-infant interaction at this level by using more than one measure of sensitivity, using toys to stimulate interaction between the mother and her infant, and coding for contingent responsiveness with more than two behaviors. Using infants who are slightly older (i.e. 4-5 months) could also be beneficial because they could initiate more interaction with their mothers (i.e. social smiling, vocalizing). A larger sample size and stricter criteria for the extreme groups would also be necessary to increase power and the likelihood of finding significant differences between the groups. 
The current study was able to establish a program of research that explored interactional styles of young infants of mothers who were sleep deprived and displayed depressive symptoms. In doing so, it was able to identify difficulties in contingent responsiveness, particularly when the mothers were highly sleep deprived and had more depressive symptoms. Future research should concentrate on identifying how these maternal characteristics are affecting the infant's subsequent development. 


\section{References}

Ainsworth, M. (1974). Infant-mother attachment and social development: 'Socialisation' as a product of reciprocal responsiveness to signals. In M. Richards (Ed.), The integration of a child into the social world (pp. 99-134). London: Cambridge University Press.

Anders, T. \& Taylor, T. (1994). Babies and their sleep environment. Childrens' Environments, $11,123-134$.

Anders, T. (1979). Night-waking in infants during the first year of life. Pediatrics, 63, 860-864. Appelbaum, M., Huston, A., Phillips, D., \& Vandell, D. (1999). Childcare and mother-child interaction in the first three years of life. Developmental Psychology, 35, 1399-1413.

Atkinson, L., Niccols, A., Paglia, A., Coolbear, J., Parker, K., Poulton, L., Gugar, S., \& Sitarenious, G. (2000). A meta-analysis of time between maternal sensitivity and attachment assessments: Implications for internal working models in infancy/toddlerhood. Journal of Social \& Personal Relationships, 17, 791-810.

Bakeman, R., \& Gottman, J.M. (1987). Applying observational methods: A systematic view. In J.D. Osofsky (Ed.), Handbook of Infant Development (pp.818-854). New York: John Wiley and Sons, INC.

Bamford, F, Bannister, R., Benjamin, C., Hillier, V., Ward, B., \& Moore, W. (1990). Sleep in the first year of life. Developmental Medicine \& Child Neurobiology, 32, 718-724.

Beck, A., Steer, R., \& Garbin, M. (1988). Psychometric properties of the Beck Depression Inventory: Twenty-five years of evaluation. Clinical Psychology Review, 8, 77-180.

Belsky, J. (1984). The determinants of parenting: A process model. Child Development, 55, 8396. 
Bigelow, A. (1998). Infants' sensitivity to familiar imperfect contingencies in social interactions. Infant Behavior and Development, 21,149-162.

Bonnet, M. (1989). Infrequent periodic sleep disruption: Effects on sleep, performance, and mood. Physiology \& Behavior, 45, 1049-1055.

Braungart-Rieker, J., Garwood, M., Powers, B., \& Wang, X. (2001). Parental sensitivity, infant affect, \& affect regulation: Predictors of later attachment. Child Development, 72, 252270.

Cohen, J. (1960). A coefficient of agreement for nominal scales. Educational \& Psychological Measurement, 10, 37-46.

Cohn, J., Cambell, S., Matias, R., \& Hopkins, J. (1990). Face-to-face interactions of postpartum depressed and nondepressed mother-infant pairs at two months. Developmental Psychology, 26, 15-23.

Cohn, J. \& Tronick, E. (1987). Mother-infant face-to-face interaction: The sequence of dyadic states at 3,6, and 9 months. Developmental Psychology, 23,_68-77.

Cottrell, L., Atkins, M., \& Khan, A. (2002). The impact of infant epilepsy on maternal sleep disruption and socio-emotional functioning. Poster presented at the International Conference on Infant Studies, Toronta, CA.

Dement, W. (1999). The promise of sleep. New York: Delacorte Press.

Dunham, P., \& Dunham, F. (1990). Effects of mother-infant social interactions on infant's subsequent contingency task performance. Child Development, 61, 785-793.

Ferber, R. (1985). Sleep, sleepiness, and sleep disturbances in infants and young children. Annals of Clinical Research, 17,227-234. 
Goodlin-Jones, B., Eiben, L. \& Anders, T. (1997). Maternal well-being and sleep-wake behaviors in infants: an intervention using maternal odor. Infant Mental Health Journal, $18,378-393$.

Hay, D. (1997). Postpartum depression and cognitive development. In L. Murray \& P. Cooper (Eds.), Postpartum Depression and Child Development. (pp.85-110). New York: Guilford Press.

Judd, C.M., Smith, E.R., \& Kidder, L.H. (1991). Research methods in social relations (6 $^{\text {th }}$ ed., pp.42-66). Forth Worth, TX: Holt, Rinehart, and Winston.

Karraker, K. \& Cottrell, L. (2000, July). Impact of sleep deprivation on socioemotional functioning of mothers and young infants. Poster presented at the International Conference on Infant Studies, Brighton, UK.

Lovejoy, M. Graczyk, P., O’Hare, E. \& Neuman, G. (2000). Maternal depression and parenting behavior: A meta-analytic review. Clinical Psychology Review, 20, 561-592.

Medoff-Cooper, B., Carey, W., \& McDevitt, S. (1993). The early infancy temperament questionnaire. Developmental \& Behavioral Pediatrics, 14, 230-235.

Murray, L. (1992). The impact of postnatal depression on infant development. Journal of Child Psychology and Psychiatry, 33, 543-561.

Murray, L. (1998). Contributions of experimental and clinical perturbations of mother-infant communication to the understanding of infant intersubjectivity. In S. Braten (Ed.), Intersubjective communication and emotion in early ontogeny. (pp.127-143). Cambridge: Cambridge University Press. 
Murray L., Fiori-Cowley, A., Hooper, R. \& Cooper, P. (1996). The impact of postnatal depression and associated adversity on early mother-infant interactions and later infant outcomes. Child Development, 67, 2512-2526.

Murray, L., Kempton, C., Woolgar, M., \& Hooper, R. (1993). Depressed mothers' speech to their infants and its relation to infant gender and cognitive development. Journal of Child Psychology \& Psychiatry, 34, 1083-1101.

Murray, L., Stanley, C., Hooper, R., King, F., \& Fiori-Cooper, A., (1996). The role of infant factors in postnatal depression and mother-infant interactions. Developmental Medicine \& Child Neurology, 38, 109-119.

Nover, A., Shore, M., Timberlake, E. \& Greenspan, S. (1984). The relationship of maternal perception and maternal behavior: a study of normal mothers and their infants. American Journal of Orthopsychiatry, 54, 210-223.

Pianta, R. \& Egeland, B. (1990). Life stress and parenting outcomes in a disadvantaged sample: Results of the mother-child interaction project. Journal of Clinical Child Psychology, 4, 329-336.

Pilcher, J. \& Huffcutt, A. (1996). Effects of sleep deprivation on performance: A Meta-Analysis. Sleep, 19, 318-326.

Snyder-Halpern, R., \& Verran, J. (1987). Instrumentation to describe subjective sleep characteristics in healthy subjects. Research in Nursing Health, 10, 155-163.

Van, Egeren, L.A., Barratt, M.S., \& Roach, M.A. (2001). Mother-infant responsiveness: Timing, mutual regulation, and interactional context. Developmental Psychology, 37, 684-697. 
Volker, S., Keller, H., Lohaus, A., Cappenburg, M., \& Chasiotis, A. (1999). Maternal interactive behavior in early infancy and later attachment. International Journal of Behavioral Development, 23, 921-936. 
Table 1

Group Differences in Self-Report Ratings on the Demographic Questionnaire

\begin{tabular}{|c|c|c|c|c|c|}
\hline \multirow[b]{3}{*}{ Measure } & \multicolumn{2}{|c|}{ Highly sleep } & \multirow{2}{*}{\multicolumn{2}{|c|}{ Not sleep deprived }} & \multirow[b]{3}{*}{$t(38)$} \\
\hline & \multicolumn{2}{|c|}{ deprived } & & & \\
\hline & $M$ & $S D$ & $M$ & $S D$ & \\
\hline Average amount of sleep & 5.90 & 0.98 & 6.85 & 0.67 & $-3.57 * * *$ \\
\hline Rating of sleep deprivation & 3.35 & 0.88 & 1.95 & 0.89 & $5.03 * * *$ \\
\hline \multicolumn{6}{|l|}{ Rating of sleep deprivation } \\
\hline negatively affecting function & 3.15 & 0.81 & 1.79 & 0.89 & $4.63 * * *$ \\
\hline \multicolumn{6}{|l|}{ Number of times sleep } \\
\hline interrupted per week & 6.32 & 1.94 & 3.52 & 2.50 & $3.95 * * *$ \\
\hline \multicolumn{6}{|l|}{ Hours of sleep needed to } \\
\hline function well & 7.50 & 0.74 & 6.70 & 1.25 & $2.46^{* *}$ \\
\hline Number of naps per week & 1.63 & 1.54 & 0.63 & 1.01 & $2.43 * *$ \\
\hline
\end{tabular}


Table 2

Group Differences in Self-Reported Behaviors on the Infant Care Diary

\begin{tabular}{|c|c|c|c|c|c|}
\hline \multirow[b]{3}{*}{ Measure } & \multicolumn{5}{|c|}{ Highly sleep } \\
\hline & \multicolumn{2}{|c|}{ deprived } & \multicolumn{3}{|c|}{ Not sleep deprived } \\
\hline & $M$ & $S D$ & $M$ & $S D$ & $t(30)$ \\
\hline
\end{tabular}

Total amount of

$\begin{array}{llllll}\text { maternal sleep per night } & 6.33 & 0.78 & 6.98 & 0.80 & -2.29 * *\end{array}$

Infant awakenings

\begin{tabular}{llllll} 
per night & 2.52 & 0.87 & 1.03 & 0.74 & $5.18^{* * * *}$ \\
\hline
\end{tabular}

$* * p<.05, * * * p<.001$ 
Table 3

Group Differences on the Verran/Snyder-Halpern Sleep Scale

\begin{tabular}{|c|c|c|c|c|c|}
\hline \multirow[b]{2}{*}{ Subscale } & \multicolumn{2}{|c|}{$\frac{\text { Highly sleep }}{\text { deprived }}$} & \multicolumn{2}{|c|}{$\underline{\text { Not sleep deprived }}$} & \multirow[b]{2}{*}{$t(37)$} \\
\hline & $M$ & $S D$ & $M$ & $S D$ & \\
\hline Disturbance & 318.32 & 133.38 & 185.26 & 136.42 & $3.08 * *$ \\
\hline Effectiveness & 235.31 & 83.41 & 295.61 & 79.70 & $2.31 * *$ \\
\hline Supplementation & 55.98 & 60.99 & 21.89 & 33.83 & $2.14 * *$ \\
\hline
\end{tabular}


Table 4

Group Differences on the Demographic Variables and Beck Depression Inventory

\begin{tabular}{|c|c|c|c|c|c|c|c|}
\hline \multirow[b]{2}{*}{ Measure } & \multirow[b]{2}{*}{ Range } & \multicolumn{2}{|c|}{ Highly Sleep Deprived } & \multicolumn{2}{|c|}{ Not Sleep Deprived } & \multirow[b]{2}{*}{$d f$} & \multirow[b]{2}{*}{$t$} \\
\hline & & $M$ & $S D$ & $M$ & $S D$ & & \\
\hline Age & 24 to 39 & 31.27 & 3.17 & 29.94 & 3.71 & 29 & 1.07 \\
\hline Income & 10,000 to 200,000 & 81450.00 & 50959.71 & 64763.16 & 43458.27 & 37 & 1.10 \\
\hline BDI & 0 to 32 & 11.45 & 8.17 & 7.79 & 5.48 & 37 & 1.63 \\
\hline
\end{tabular}

Note. $\mathrm{BDI}=$ total score on the Beck Depression Inventory.

${ }^{a} p>.05$ 
Table 5

The Distribution of Employment Status, Education Level, Spouse Education, Race, and Spouse Race in the Sample

\begin{tabular}{|c|c|c|}
\hline \multirow[b]{2}{*}{ Variable } & \multicolumn{2}{|c|}{ Frequency } \\
\hline & Highly Sleep Deprived & Not Sleep Deprived \\
\hline \multicolumn{3}{|l|}{ Education Level } \\
\hline High school, no college & 0 & 1 \\
\hline Some college & 4 & 4 \\
\hline Four year college & 5 & 7 \\
\hline Some graduate school & 11 & 8 \\
\hline \multicolumn{3}{|l|}{ Spouse Education } \\
\hline High school, no college & 0 & 2 \\
\hline Some college & 2 & 4 \\
\hline Four year college & 6 & 6 \\
\hline Some graduate school & 12 & 8 \\
\hline \multicolumn{3}{|l|}{ Race } \\
\hline Non-Hispanic White & 19 & 20 \\
\hline African American & 0 & 0 \\
\hline Native American & 1 & 0 \\
\hline Other & 0 & 0 \\
\hline
\end{tabular}

Spouse Race 


\begin{tabular}{lcc} 
Non-Hispanic White & 18 & 19 \\
African American & 0 & 1 \\
Native American & 1 & 0 \\
Other & 1 & 0 \\
\hline
\end{tabular}


Table 6

Mean Early Infancy Temperament Questionnaire Ratings

\begin{tabular}{|c|c|c|c|c|c|}
\hline \multirow[b]{2}{*}{ Subscale } & \multicolumn{2}{|c|}{$\frac{\text { Highly sleep }}{\text { deprived }}$} & \multicolumn{2}{|c|}{ Not sleep deprived } & \multirow[b]{2}{*}{$t(37)$} \\
\hline & $M$ & $S D$ & $M$ & $S D$ & \\
\hline Activity & 3.85 & 1.06 & 3.73 & 0.86 & 0.39 \\
\hline Rythmicity & 3.26 & 0.88 & 3.41 & 1.39 & -0.41 \\
\hline Approach & 2.64 & 0.82 & 2.85 & 0.89 & -0.75 \\
\hline Adaptability & 2.40 & 0.81 & 2.44 & 1.00 & -0.15 \\
\hline Intensity & 3.65 & 0.78 & 3.65 & 0.85 & -0.01 \\
\hline Mood & 2.59 & 0.41 & 2.38 & 0.60 & 1.28 \\
\hline Persistence & 2.07 & 0.66 & 2.10 & 1.16 & -0.12 \\
\hline Distractibility & 1.89 & 0.57 & 2.00 & 0.68 & -0.51 \\
\hline Threshold & 4.24 & 0.85 & 4.50 & 0.81 & -0.96 \\
\hline GI activity & 4.95 & 0.83 & 5.00 & 0.75 & -0.20 \\
\hline GI rhythmicity & 2.80 & 1.10 & 2.63 & 1.21 & 0.45 \\
\hline GI approach & 1.70 & 0.86 & 1.58 & 0.84 & 0.44 \\
\hline GI adaptability & 1.89 & 0.88 & 1.80 & 0.63 & 0.43 \\
\hline GI intensity & 3.85 & 1.38 & 4.06 & 1.11 & -0.50 \\
\hline GI mood & 1.70 & 1.17 & 1.42 & 0.61 & 0.92 \\
\hline GI persistence & 2.50 & 0.89 & 2.37 & 1.01 & 0.43 \\
\hline
\end{tabular}




\begin{tabular}{lccccc} 
GI distractibility & 3.10 & 1.02 & 3.63 & 1.26 & -1.45 \\
GI threshold & 3.75 & 1.16 & 4.00 & 1.10 & -0.69 \\
& & & & & \\
Manageability & 1.95 & 1.05 & 1.42 & 0.61 & $1.91^{*}$ \\
\hline
\end{tabular}

Note. GI=general impression of the infant's temperament in comparison with other infants known by the mother who are the same age.

${ }^{*} \mathrm{p}<.10$. 
Table 7

Mean Group Differences on the Dependent Variables

\begin{tabular}{|c|c|c|c|c|c|c|}
\hline \multirow[b]{2}{*}{ Dependent Variable } & \multicolumn{2}{|c|}{$\frac{\text { Highly Sleep }}{\text { Deprived }}$} & \multicolumn{2}{|c|}{$\frac{\text { Not Sleep }}{\text { Deprived }}$} & \multirow[b]{2}{*}{$d f$} & \multirow[b]{2}{*}{$t^{\mathrm{a}}$} \\
\hline & $M$ & $S D$ & $M$ & $S D$ & & \\
\hline Maternal Sensitivity & 7.31 & 0.45 & 7.26 & 0.64 & 38 & 0.31 \\
\hline$z$ ISMS & -2.71 & 1.90 & -2.99 & 4.90 & 31 & 0.21 \\
\hline z ISMV & -8.41 & 4.53 & -5.82 & 3.57 & 19 & -1.47 \\
\hline$z$ IVMS & -2.54 & 1.84 & -3.83 & 4.38 & 32 & 1.15 \\
\hline$z$ IVMV & -6.81 & 4.25 & -8.09 & 3.01 & 22 & 0.86 \\
\hline$z$ ISVMSV & -8.39 & 3.30 & -11.19 & 4.97 & 19 & 1.40 \\
\hline \multicolumn{7}{|l|}{ Maternal Agreement } \\
\hline with Sleep Statement & 1.80 & 1.06 & 1.30 & 0.98 & 38 & 1.54 \\
\hline
\end{tabular}

Note. IS=infant smile; IV=infant vocalize; ISV=infant smile or vocalize; $\mathrm{MS}=$ mother smile; $\mathrm{MV}=$ mother vocalize; $\mathrm{MSV}=$ mother smile or vocalize; $z=\mathrm{z}$-scores for the transitional probabilities that were calculated for the first behavior being followed by the second behavior. ${ }^{a} p>.05$ 
Table 8

Descriptive Statistics for the Contingent Responsiveness Base Probabilities

\begin{tabular}{|c|c|c|c|c|c|c|}
\hline \multirow[b]{2}{*}{ Probability } & \multirow[b]{2}{*}{ Range } & \multicolumn{2}{|c|}{$\frac{\text { Highly sleep }}{\text { deprived }}$} & \multicolumn{2}{|c|}{ Not sleep deprived } & \multirow[b]{2}{*}{$t^{\mathrm{a}}(38)$} \\
\hline & & $M$ & $S D$ & $M$ & $S D$ & \\
\hline Infant smile & $.00-.38$ & 0.12 & 0.12 & 0.08 & 0.10 & 1.13 \\
\hline Infant vocalize & $.00-.73$ & 0.18 & 0.21 & 0.20 & 0.17 & -0.39 \\
\hline Infant smile or vocalize & $.00-.73$ & 0.26 & 0.20 & 0.26 & 0.16 & -0.06 \\
\hline Mother smile & $.00-.98$ & 0.52 & 0.23 & 0.48 & 0.28 & 0.49 \\
\hline Mother vocalize & $.66-1.00$ & 0.92 & 0.10 & 0.92 & 0.08 & -0.06 \\
\hline Mother smile or vocalize & $.77-1.00$ & 0.96 & 0.06 & 0.95 & 0.06 & 0.31 \\
\hline
\end{tabular}


Table 9

Summary of Regression Analyses for Sleep Deprivation and Maternal Depression Predicting Sensitivity and Contingent Responsiveness

\begin{tabular}{lcccccc}
\hline \multicolumn{1}{c}{\begin{tabular}{c}
\multicolumn{2}{c}{$B$} \\
$\begin{array}{c}\text { Dependent } \\
\text { variable }\end{array}$
\end{tabular}} & $\begin{array}{c}\text { BDI } \\
\text { total }\end{array}$ & Group & $\begin{array}{c}\text { BDI } \\
\text { total }\end{array}$ & Group & $\begin{array}{c}\text { BDI } \\
\text { total }\end{array}$ & Group \\
\hline Sensitivity & -0.01 & -0.12 & 0.01 & 0.18 & -0.20 & -0.11 \\
$z$ ISMS & -0.13 & -0.83 & 0.09 & 1.35 & -0.26 & -0.11 \\
$z$ ISMV & -0.04 & 2.32 & 0.13 & 2.00 & -0.08 & 0.29 \\
$z$ IVMS & -0.19 & -1.97 & 0.09 & 1.12 & -0.35 & -0.30 \\
$z$ IVMV & -0.11 & -1.83 & 0.11 & 1.60 & -0.27 & -0.26 \\
$z$ ISVMSV & -0.28 & -4.53 & 0.13 & 2.00 & $-0.47 * *$ & $-0.50^{* *}$ \\
\hline
\end{tabular}

Note. IS=infant smile; IV=infant vocalize; ISV=infant smile or vocalize; $\mathrm{MS}=$ mother smile; $\mathrm{MV}=$ mother vocalize; $\mathrm{MSV}=$ mother smile or vocalize; $z=\mathrm{z}$-scores for the transitional probabilities that were calculated for the first behavior being followed by the second behavior. $* * \mathrm{p}<.05$. 
Table 10

Coder 1 and Coder 2's Ratings of Sensitivity

\begin{tabular}{|c|c|c|c|c|c|c|}
\hline \multirow[b]{3}{*}{ Coder 1} & \multirow[b]{2}{*}{ Range } & \multicolumn{2}{|c|}{$\frac{\text { Highly Sleep }}{\text { Deprived }}$} & \multicolumn{2}{|c|}{$\frac{\text { Not Sleep }}{\text { Deprived }}$} & \multirow[b]{2}{*}{$t^{a}(38)$} \\
\hline & & $M$ & $S D$ & $M$ & $S D$ & \\
\hline & $6.00-8.33$ & 7.12 & 0.47 & 6.98 & 0.48 & 0.94 \\
\hline Coder 2 & $5.67-9.00$ & 7.50 & 0.61 & 7.53 & 0.99 & -0.13 \\
\hline
\end{tabular}


Table 11

Intercorrelations Among the Different Measures of Sleep

\begin{tabular}{lcccccccc}
\hline \multicolumn{1}{c}{ Measure } & 1 & 2 & 3 & 4 & 5 & 6 & 7 & 8 \\
\hline 1. DQ \# 6 & - & -0.14 & 0.09 & $0.55^{* * *}$ & -0.03 & -0.27 & $0.36^{* *}$ & -0.15 \\
2. DQ \#10 & -0.14 & - & 0.25 & -0.19 & $0.63 * * *$ & $0.39 * *$ & -0.23 & 0.22 \\
3. DQ \#12 & 0.09 & 0.26 & - & 0.07 & -0.01 & -0.01 & 0.11 & 0.13 \\
4. ICD: MST & $0.56^{* * *}$ & -0.19 & 0.07 & - & -0.08 & -0.23 & $0.62 * * *$ & -0.27 \\
5. ICD: MWF & -0.03 & $0.63 * * *$ & -0.01 & -0.08 & - & $0.52 * * *$ & -0.19 & $0.63 * * *$ \\
6. SS: Disturb & -0.27 & $0.39 * *$ & -0.01 & -0.23 & $0.52^{* * *}$ & - & -0.25 & $0.43 * * *$ \\
7. SS: Effective & $0.36^{* *}$ & -0.23 & 0.11 & $0.62 * * *$ & -0.19 & -0.25 & - & -0.14 \\
8. SS: Suppl & -0.15 & 0.22 & 0.13 & -0.27 & $0.63 * * *$ & $0.43 * * *$ & -0.14 & \\
\hline
\end{tabular}

Note. DQ\#6=Average amount of sleep as reported on the demographic questionnaire;

DQ\#10=Number of times sleep is interrupted as reported on the demographic questionnaire;

DQ\#12=Amount of sleep needed to function well; ICD: MST=Mother sleep total for the week as reported on the Infant Care Diary; ICD: $\mathrm{MWF}=$ Mother wake frequency for the week as reported on the Infant Care Diary; SS: Disturb= The disturbance subscale of the Verran/Snyder-Halpern Sleep Scale; SS: Effective=The effectiveness subscale of the Verran/Snyder-Halpern Sleep Scale; SS: Suppl=The supplementation subscale of the Verran/Snyder-Halpern Sleep Scale. $* * p<.05, * * * p<.001$ 
Appendix A 
Date:

1. What is your current age?

2. Is this your first child? Yes/No (please circle). If not, how many children do you have?

3. Please indicate your child's birth date: and type of delivery:

4. What is your infant's gender (please circle)? Male Female

5. Was he/she born prematurely? Yes/No (please circle). If so, by how many weeks?

6. Has your infant has any medical problems since birth? Yes/No (please circle). If yes, please describe:

7. Please indicate the method in which you feed your baby:

8. How much does your baby cry on average (please circle)?

0-1 hr/day 2-3 hrs/day 3-4 hrs/day more than $4 \mathrm{hrs} /$ day

9. How many times does your infant typically wake up during the night (while you are sleeping)?

10. On average, what is the longest period of time your infant remains asleep at night?

11. Please check the number of hours you get on average per night:

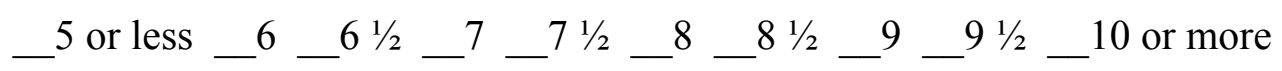

12. Please indicate the number of hours of sleep per night you need to function well:

13. Please indicate the number of naps you take per day and the average length of each: \# of naps average time spent sleeping during nap:

Thank you for your interest in our study of mothers' interactions with young infants. Please give your current name, address, and telephone number to enable us to contact you concerning participation in our study:

Name:

Telephone Number:

Address: 
Appendix B 
Subject \#:

Date:

Time of Appointment:

\section{Information about you}

1. Current employment status:

\section{Background Questionnaire}

Full time: \# of hours per week:

Part time: \# of hours per week:

Volunteer: \# of hours per week:

_ Homemaker

2. Please list your occupation/job title:

3. Please indicate your current level of education:

Without high school diploma

_ High school graduate, no college

_ Some college education

- 4-year college degree

_ Some graduate school

(specify degree:

4. If you are not currently working, do you plan on returning to work? Yes/No (please circle) If so, when? When my baby is months/years old (circle one).

5. Rate your general mood today:
1
2
3
4
5
very negative
very positive

6. How many hours of sleep per night do you get on average?

7. Please indicate the number of hours of sleep you get on weeknights and weekends

8. What time do you get up in the morning? weeknight and weekend

9. What time do you go to bed at night? weeknight and weekend

10. How many nights per week is your sleep interrupted? (out of 7)

11. How many nights per week is your sleep interrupted by:

your baby waking you another child waking you your husband/partner waking you
Typical length of interruption: $\mathrm{sec} / \mathrm{min} / \mathrm{hrs}$ (circle one) $\mathrm{sec} / \mathrm{min} / \mathrm{hrs}$ (circle one) $\mathrm{sec} / \mathrm{min} / \mathrm{hrs}$ (circle one) 
not being able to sleep $\mathrm{sec} / \mathrm{min} / \mathrm{hrs}$ (circle one) other $\mathrm{sec} / \mathrm{min} / \mathrm{hrs}$ (circle one)

Please describe:

12. How much sleep do you need to function well?

13. How much sleep per night would be ideal for you?

14. How important is it to you that you get enough sleep?

1

not important
3
4 very important

15. Do you take naps? Yes/No (please circle) If so, please indicate how many times per week you take a nap.

16. Rate your current level of sleep deprivation:

$\begin{array}{ccccc}1 & 2 & 3 & 4 & 5 \\ \begin{array}{c}\text { not sleep } \\ \text { deprived }\end{array} & & & & \begin{array}{c}\text { very sleep } \\ \text { deprived }\end{array}\end{array}$

17. If you think you are sleep deprived to what extent do you think your everyday functioning is negatively affected?

$\begin{array}{ccccc}1 & 2 & 3 & 4 & 5 \\ \text { not at all } & & & & \text { a great deal }\end{array}$

18. If you think you are sleep deprived to what extent do you feel it is interfering with your ability to interact with your baby?
1
2
3
4
5
not at all
a great deal

Information about your baby

1. Please indicate your child's gender (circle one): Male Female

2. What time did your baby last awaken from a nap and how long was it (please indicate the time/length)?

3. When was your baby last fed (please indicate the time)?

4. Please indicate any health problems your baby has had since birth: 
5. Please indicate the approximate time that you put your baby to bed each night:

6. When you put your baby to bed is he or she typically awake or asleep? (circle one)

7. Where does your baby typically sleep at night?

- Bassinet or crib in parents' room

Bassinet or crib in own room

- Bassinet or crib in sibling room

In bed with (please indicate)

Other or combination (please indicate)

8. Please indicate the number of times your baby awakens each night:

9. Who typically cares for your baby when he/she awakens during the night?

10. If you share nighttime care, what percent of the time do you care for your baby when he/she awakens during the night?

11. Please indicate what you do to get your baby back to sleep during the night:

\section{Information about your household:}

1. Please list all people living in your home (i.e. husband/partner, older children, relatives):

2. If you are in a relationship, what is your husband/partner's job title/occupation?

(Please indicate if unemployed)

3. Please indicate your husband/partner's current education level:

Without high school diploma

— High school graduate without college education

- Some college education

— 4-year college degree

- Some graduate school

(specify degree:

4. Please indicate your race/ethnicity:

Non-Hispanic White

Hispanic

African American

Native American 
Asian/Pacific Islander

Other (please indicate):

5. Please indicate your partner's race/ethnicity:

Non-Hispanic White

Hispanic

African American

Native American

Asian/Pacific Islander

Other (please indicate):

6. Please report your yearly household income: 
Appendix C 
Subject \#:

Date:

\section{$\underline{\text { Rating of Interaction (Mother) }}$}

1. How typical was your baby's behavior during the interaction? Did he/she play the way he/she usually does?

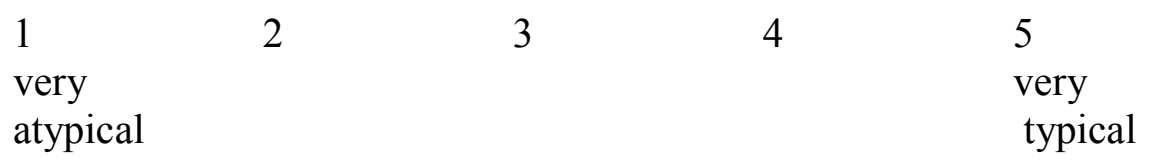

2. Please rate how active your infant was with you throughout the interaction:

$\begin{array}{ccccc}1 & 2 & 3 & 4 & 5 \\ \text { very still } & & & & \text { very active }\end{array}$

3. Please rate the level of happiness your infant expressed during the interaction:

$\begin{array}{lllcc}1 & 2 & 3 & 4 & 5 \\ \text { very sad } & & & & \text { very happy }\end{array}$

4. Please rate the overall interaction with your baby:

$\begin{array}{ccccc}1 & 2 & 3 & 4 & 5 \\ \text { poor } & \text { somewhat poor } & \text { average } & \text { good } & \text { excellent }\end{array}$

5. Please rate your level of agreement with the following statement: I would have had a higher quality interaction with my infant if I had gotten more sleep last night.

$\begin{array}{lllll}1 & 2 & 3 & 4 & 5 \\ \text { strongly } & & & & \begin{array}{l}\text { strongly } \\ \text { agree }\end{array} \\ \text { disagree } & & & & \end{array}$

6. Please list any factors that you believe affected your interaction with your infant: 
7. Please check the following factors that influenced your interaction with your infant: My infant was cranky/fussy.

I was in a good mood. My infant was inactive.

I was in a bad mood.

My infant was happy.

I was overly tired.

My infant's behavior was atypical.

I was distracted. 
Appendix D 


\section{General Sensitivity}

1. Completely inattentive and insensitive to baby's state and baby's play. Completely unresponsive to obvious cues.

2. Shows no sensitivity to baby's state and play, but not actively insensitive, mildly inappropriate actions.

3. While aware of baby's state, mother disregards cues and continues her mildly inappropriate actions.

4. Mother is slightly insensitive with variable attention and shows general insensitivity.

5. Intermittent accommodation and sensitivity to baby's needs.

6. Mother is generally sensitive though some few moments of slightly insensitive behavior may be seen.

7. Mother is sensitive to the baby and usually reacts with accommodating responses.

8. Sensitive to baby's state and needs; almost always accommodating or responsive to baby's cues and needs.

9. Sensitive to baby's states and needs at all times, always responsive and attentive 